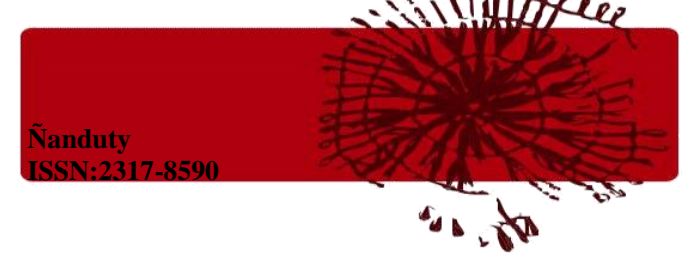

\title{
KURÂ ITANRO: COSMOPOLÍTICA E LÍNGUA ENTRE OS BAKAIRI
}

\author{
Evandro Bonfim (CEBRAP/FAPESP evandrobonfim@ @otmail.com) ${ }^{1}$
}

\begin{abstract}
Resumo: A interação semiótica entre humanos e não humanos para muitos ameríndios envolve mais do que processos de significação através de ícones e índices, pois para se realizarem exigem a utilização das línguas faladas pelos próprios povos e, muitas vezes, também das línguas estrangeiras das diversas alteridades com que se engajam. $\mathrm{O}$ artigo tem como objetivos mostrar, através do caso da língua Bakairi (Karib), como os idiomas indígenas estão atravessados por questões que dizem respeito às relações de alianças e conflitos com entes e potências de distintas categorias ontológicas, ou seja, por relações cosmopolíticas. E a partir da relação entre cosmopolítica e língua, presentes, por exemplo, no léxico somático dos Bakairi, o artigo propõe o conceito de "gramática cosmopolítica" como maneira de qualificar a discussão sobre política linguística para idiomas ameríndios.
\end{abstract}

PALAVRAS-CHAVE: Bakairi (Karib), Língua, Gramáticas Cosmopolíticas

\begin{abstract}
The semiotic interaction between humans and nonhumans for many Amerindians involves more than signification processes through icons and indexes, because in order to perform it the languages spoken by the peoples themselves are required, and often also of the foreign languages of the various Alterities with which they engage. The article aims to show, through the Bakairi (Karib) language case, how the indigenous languages are entangled by questions related to the relations of alliances and conflicts with entities and powers of different ontological categories, that is, by cosmopolitical relations. The article proposes the concept of "cosmopolitical grammar" as a way of qualifying the discussion on linguistic policy for Amerindian languages, based on the relationship between cosmopolitics and language, for example in the Bakairi somatic lexicon.
\end{abstract}

KEY WORDS: Bakairi (Karib), Language, Cosmopolitical Grammar

A questão da linguagem tem ocupado lugar especial nas críticas antropológicas pós-estruturalistas. Existe, no entanto, pouca ou nenhuma reflexão sobre as abordagens acerca da linguagem que vêm se acumulando no pensamento antropológico recente em substituição ao modelo estrutural linguístico. Autores como Latour (1995), dentre outros, buscam restaurar a imbricação constituinte entre "as palavras e as coisas" e o potencial perfomativo da enunciação, evitando tomar a língua como domínio analítico em separado, posição clássica advinda da noção do objeto da Linguística elaborado por Saussure, que permitiu, por exemplo, à Lévi-Strauss (2008 [1958]) desenvolver o conceito de "mitema". As novas perspectivas vão se valer principalmente do instrumental teórico da Pragmática, sobretudo de autores como Peirce, Austin e Searle,

\footnotetext{
${ }^{1}$ Doutor em Antropologia Social pelo PPGAS/Museu Nacional-UFRJ. Pesquisador do Centro Brasileiro de Análise e Planejamento (CEBRAP) com bolsa de Pós-Doutorado da FAPESP (2015/26464-9).
} 




para tratar de fenômenos linguageiros, sobrando pouco espaço para temas antes tão caros à Antropologia como as consequências da diferença linguística.

Uma das mais recentes expressões da relação entre pensamento antropológico e pragmatista se encontra nas "florestas pensantes" de Eduardo Kohn (2013). O autor utiliza a experiência etnográfica com a população falante de quéchua Runa Puma para admoestar a disciplina antropológica a ir "além do humano", o que significa, para ele, ir além do linguístico. "We conflate representation with language in the sense that we tend to think how representation works in terms of our assumptions of how human language works", afirma (2013:8). Para Kohn, "life is constitutively semiotic", quer dizer, todas formas de vida "representam", ou seja, realizam o processo semiótico de estabelecer sentidos.

Os não humanos, contudo, dispensariam a utilização de símbolos, os quais, dentro da concepção triádica do signo elaborada por Peirce, dizem respeito às relações convencionalizadas entre a forma sígnica e referentes. Dentre os símbolos peirceanos encontra-se precisamente os termos que compõem o sistema das línguas descritos por Saussure através da relação entre imagem acústica e conceito (significante-significado). Assim, humanos e não humanos compartilhariam os dois outros elementos semióticos: o índice, que traz consigo as relações de dêixis, e o ícone, onde prevalecem as relações de semelhança.

No entanto, para os Bakairi - povo de língua Karib que vive no Centro-Oeste do Brasil $^{2}$ - os não humanos falam uma língua plena, o Anguido Itanro. Anguido são os seres primordiais que viviam na época quando tudo era escuridão. Atualmente, o termo anguido se refere igualmente aos animais, originados dos entes primevos que não foram iluminados pelo gêmeo solar, e a pessoas assemelhadas a eles como as bruxas, chamadas de anguidokula (coisa do tipo anguido). Também podem falar o Anguido Itanro os espíritos de mortos kadopa ao possuir animais como sapos (pururu) e morcegos (semimo) que causam malefícios aos Bakairi. Somente o xamã (piaje) domina completamente o Anguido Itanro, sendo assim capaz de conversar - e distinguir anguido de kadopa quando as formas corpóreas se apresentam como as mesmas. Outros não humanos como as máscaras animadas pelos espíritos Iamyra usam a mesma língua

\footnotetext{
2 Os Bakairi somam cerca de 1.100 pessoas ocupando duas terras indígenas, a Santana e a Bakairi, localizadas no estado de Mato Grosso. Grande parte do povo indígena se compõe de descendentes de alto xinguanos, obrigados a migrar pelo Estado a partir das famosas expedições de Karl von den Steinen no final do século XIX. O autor realiza pesquisa de campo etnográfica e linguística junto aos Bakairi desde 2013 nas aldeias Pakuera e Kaiahoalo.
} 


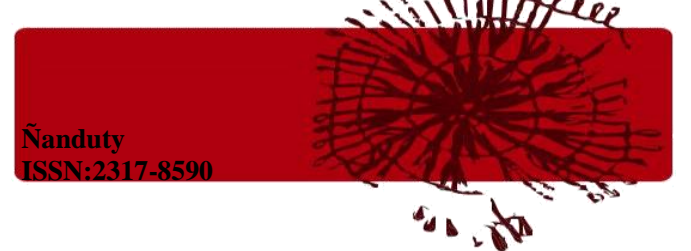

dos Bakairi, o Kurâ Itanro (língua de gente), ao entoar canções que organizam a vida moral do povo durante a cerimônia do Kado.

Portanto, a teia de semiose que Kohn associa de maneira biologizante às formas de vida silvanas, entre os Bakairi se estende a tipos de mortos (espíritos) e categorias de seres com existências especiais (máscaras, bichos) que transitam entre as lógicas do mito, do ritual e mesmo do comezinho. E, mais importante, não se limitam a utilização de indíces e ícones, mas antes os englobam na formação dos diversos Itanro, as línguas, faladas por eles nos mais distintos tipos de engajamentos com os Bakairi.

Tais ações, que envolvem alianças e conflitos com entes e potências de distintas categorias ontológicas, têm sido chamadas de "cosmopolítica" por aqueles que pesquisam os coletivos ameríndios (SZTUTMAN 2012, LIMA 2011). Os idiomas falados pelos povos indígenas também são atravessados pelas questões cosmopolíticas, visto que a língua também está inserida na trama das relações cosmológicas, sendo decisiva para que intercâmbios, negociações e embates espirituais envolvidos em instâncias como a arte xamânica, por exemplo, aconteçam.

Assim, com base em coleta de dados linguísticos em primeira mão e trabalho de campo de cunho etnográfico, o texto vai apresentar algumas das principais relações entre aspectos gramaticais e a organização ontológica do povo indígena, mostrando como o contato com as alteridades não humanas e o mito afetam a estrutura do Kurâ Itanro. A discussão será focada nos componentes semânticos e funcionais do léxico somático do idioma Karib, evidenciando como as preocupações cosmológicas atuam nas categorias linguísticas, mesmo as mais formais. Em conclusão, se buscará unir a questão da política linguística relativa a idiomas ameríndios com a abordagem cosmopolítica, lançando fundamentos para a elaboração de uma Gramática Cosmopolítica do Bakairi.

\section{MARCAS GRAMATICAIS DO CORPO HUMANO E NÃO HUMANO}

As partes do corpo são um campo semântico interessante para se procurar relações entre propriedades gramaticais e os princípios de constituição da pessoa, principalmente nos povos ameríndios, entre os quais prevalece a noção de fabricação corporal contínua através de intervenções periódicas tanto humanas como não humanas (VIVEIROS DE CASTRO 1979). As partes do corpo em Bakairi, como em inúmeras línguas indígenas, são inalienáveis, i.e., são sempre possuídas. Contudo, desde Von den Steinen (1892), a 


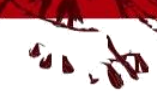

obtenção das palavras acerca dos elementos corporais aponta para o prefixo de dual inclusivo $k-\sim k i$ - como possuidor default.

No entanto, a pessoa dual inclusiva em Bakairi, que traz kura como forma independente, não se restringe ao escopo pronominal, pois significa igualmente "gente", em oposição à anguido (animais), além de ser a autodenominação dos Bakairi para os não-indígenas (SOUZA 1999).Os dados abaixo vão mostrar em primeiro lugar que morfemas representando determinados componentes somáticos inalienáveis só se realizam na língua quando categorizados como gente ou não gente.

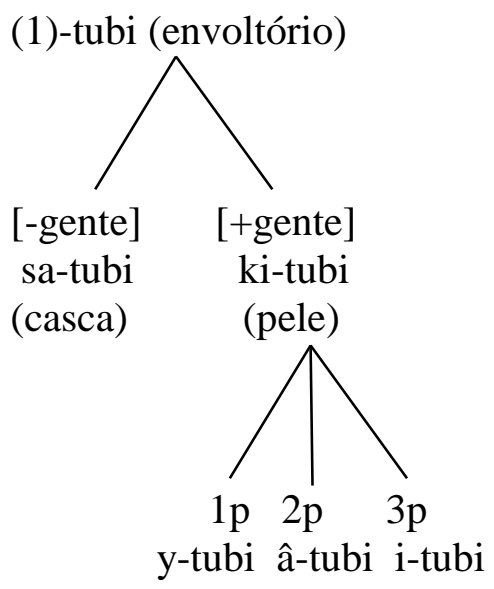

O paradigma dos prefixos de posse também atribui traço [+gente] ao morfema lexical somático «envoltório», conferindo assim o sentido de "pele", devidamente possuída. No entanto, diz respeito basicamente à oposição entre pessoas gramaticais, não operando necessariamente a oposição entre categorias de seres, visto que são marcas não relacionais. Somente o prefixo do dual inclusivo traz o sentido de mútuo reconhecimento do traço [+gente] entre duas pessoas discursivas e gramaticais, tornando possível o compartilhamento e a identificação dentro do táxon gente em oposição ao correspondente não humano, o envoltório vegetal, a casca (marcado pelo prefixo $\mathrm{SV}$-, relativo à $3 \mathrm{p}[$-animado $])^{3}$.

É interessante que oposições podem surgir no interior do paradigma de marca de posse revelando nuances do traço [gente] e justificando a preferência por ele em comparação com outras soluções mais usuais da análise linguística como o traço [animado]. Por exemplo, o morfema lexical somático -mida que corresponde ao

\footnotetext{
${ }^{3}$ Ver, por exemplo, a oposição entre demonstrativos que atuam como pronomes de terceira pessoa para humanos, awaka e maka em relação aos demonstrativos para coisas, xira e xura. O ponto de articulação da sibilante em Bakairi está condicionado à vogal que a acompanha, se tornando palatalizadas diante de vogais altas.
} 


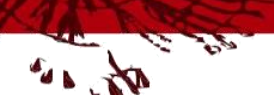

componente corporal «cara» tem o sentido de "cara humana" (rosto) quando precedido do prefixo dual inclusivo (ka-mida) e tem o sentido de "cara sobrenatural" (máscara) quando o prefixo utilizado se refere a terceira pessoa singular (i-mida, "a cara dele"). As máscaras são plenos agentes da vida social Bakairi por se tratarem de instanciações materiais dos espíritos do Kado ou iamyra, conforme dito anteriormente. As máscaras se alimentam e vão adquirindo corpo (cores e plumagem de buriti) antes de saírem para conviver com os Bakairi no ritual do Iakuigâdy ${ }^{4}$.

De acordo com o mito que conta a destruição dos antecessores da atual geração Bakairi, a quebra do tabu relativo à casa dos homens (Kadoety ou casa do Kado) por um jovem foi punida com a fixação permanente da máscara no rosto do rapaz, que ficou sem a face humana, mas com face de madeira. Assim, ambos são "gente", mas os espíritos do Kado, com máscaras no lugar do rosto e restante do corpo humano por estarem incorporados nos homens Bakairi, recebem o traço de não-pessoa próprio das marcas de terceira pessoa (cf. BENVENISTES 1989), situando-se, portanto, no limite da categoria.

A violação da regra da reclusão na casa dos homens conduz a outro item do léxico somático importante para o esboço de Gramática Cosmopolítica aqui apresentado. $\mathrm{O}$ ato do jovem Bakairi trouxe a ruína para todo grupo, que resolveu festejar em uma casa trancada e depois atear fogo provocando a extinção da geração. Somente um casal de crianças foi preservado. No dia seguinte à festa, eles encontram no local do incêndio um milharal, descobrindo que das espigas renasceram os Bakairi. Este mito não está registrado apenas na memória dos indígenas, mas se encontra também inscrito na língua através da palavra para "esqueleto":

(2) t-ânji-byre

posse generalizada-milho-ex

Como parte do corpo, o esqueleto também é inalienável. Porém, ao contrário dos exemplos "pele" e "rosto" tratados anteriormente, o vocábulo não aparece com a marca do dual inclusivo, mas sim com o prefixo de posse generalizada, presente, por exemplo, nos termos cromáticos. No lugar do morfema indicando partes do corpo encontra-se o nome milho, item lexical reconhecido pelos informantes como integrante da palavra

\footnotetext{
${ }^{4}$ De acordo com Barcelos Neto (2008), Iakui são as máscaras de madeira e buriti dos rituais de máscara dos Waujá, dentro do complexo xinguano do qual os Bakairi já fizeram parte. Assim, os espíritos Kado (gâdy no interior das palavras devido a modificações fonéticas) com as faces amadeiradas são o Iakuigâdy.
} 


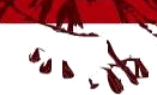

"esqueleto". Conforme visto na breve descrição do mito da extinção pelo fogo, os atuais Bakairi se tornaram gente a partir do milho. A metamorfose mítica está indicada pelo sufixo -byre que indica a mudança entre certo estado para outro como em saguhobyre, os que deixaram de ser os primeiros, ou seja, os velhos, dentro da sequência invertida própria do pensamento Bakairi (SOUZA 1991) que impede a identificação automática do sufixo com o tempo passado.

Mas no caso em pauta se mostra válida a interpretação da sufixação como expressando o processo de deixar de ser milho, a mudança da antiga estrutura corpórea do cereal para a do corpo Bakairi contemporâneo, proveniência que sempre será apontada pela língua enquanto o mito se mantiver relevante para o povo Bakairi. Tratase assim de um signo com motivação semântica, expressando uma relação de iconicidade cosmológica na qual a palavra expressa propriedades do referente, o corpo mitológico, que no caso não está separado do que se considera o corpo biológico.

\section{COSMOPOLÍTICA LINGUÍSTICA}

Durante a festa chamada ÂnjiItabienly (batizado do milho), os Bakairi jogam grãos de milho na terra (orrõ) quatro vezes. "A gente joga milho nos cantos que corre o vento. $\mathrm{O}$ vento espalha milho sobre toda terra e do milho nasce Bakairi. Por isso, Bakairi nunca vai deixar de existir", contam (SOUZA 1999:12). Atualmente o batizado do milho tem sido realizado com menos frequência por conta da escassez do milho próprio dos Bakairi, o milho kurâ, termo que acumula os sentidos de gente, autodenominação do povo e pessoa dual inclusiva, significados entrelaçados por fios linguísticos, históricos, mitológicos e cerimoniais que descartam a possibilidade de homonímia. Plantações de milho kurâ e os buritizais de onde se retirar as matériasprimas das máscaras se encontram fora do reduzido território Bakairi, nas fazendas dos não-indígenas (karaiwa). Neste ponto, a questão política da terra impede a plena realização da verdadeira existência Bakairi, expressa pelas noções de corpo e pessoa presentes nos rituais, na vida cotidiana, na alimentação, na estética e - conforme visto nos exemplos tratados aqui - em componentes da gramática. A esta cadeia de relações, vista sob o ponto de vista da língua, estamos dando o nome de Gramática Cosmopolítica.

A elaboração de uma Gramática Cosmopolítica envolve assim a tentativa de compreender a língua da forma mais sistêmica possível, buscando as relações entre os elementos linguísticos não apenas em domínios classicamente circunscritos como 
